\title{
Education, Research, and Dishwashers in the Time of COVID-19
}

\author{
Dr. John A. Heitmann \\ The effect of COVID-19 on supply chains is introduced and some parallels \\ are drawn with its effects on education and research. The default option \\ in education seems to be distance education, which is already difficult for \\ colleges and universities, but much more so for K-12. The effect of \\ COVID-19 on research is much more varied. Some areas, like health \\ sciences, are intensified while others, such as academic research, are \\ anticipating declines in activity. It is expected that international graduate \\ students will be more adversely affected than other groups. Some \\ thoughts on the "new normal" are presented.
}

Keywords: COVID-19; Supply chain effects; Education; Research

Contact information: Professor Emeritus, Department of Forest Biomaterials, Campus Box 8005, North Carolina State University, Raleigh, NC 27695-8005, USA; * email: heitmann@ ncsu.edu

\section{Supply Chain Effects}

Recently I retired, became an emeritus professor and began learning to cook. I enjoy cooking because it involves artistic effort, science and occasionally engineering. So far the only bad side effect has been weight gain. I aspire to achieve mastery of cooking but currently I am only about a sophomore.

A few weeks ago, my dishwasher experienced a massive stroke. Fortunately, it was only a machine and my repairman diagnosed a complete digital failure, a need-a-wholenew-control-system condition, and gave me a smarter-to-buy-a-new-one prescription. The next day at a large retailer there were dozens to select from and I quickly chose a few good candidates. The sales person explained that they were all available, just not now. Three weeks, six weeks, even as far as six months out! Plus, a wait of one to three weeks to arrange for installation. I was already tired of washing dishes. I asked about the one on sale with the big signs. They had 1091 of them. All were back ordered with no known delivery date in sight. It was a supply chain thing, you know.

It is a creative and interesting process to speculate on how the supply chain became so fouled up, especially when income depends on it and presumably professionals are operating it. One envisions uncertainty due to COVID-19 shutdowns, being shut down with a large supply chain inventory, warehouses overflowing and needing guards, maintenance, and increasing debt. But then what if that does not happen? Supply chains are not my area of expertise but I do have a little experience with them . . . mostly bad. They have some characteristics in common with trains, or pipelines, or rivers. They are hard to speed up and slow down and sudden stops are really not easy! This is especially true for big supply chains like big retailers have, or industries (think pharmaceuticals) or countries (think USA, China). Sudden stops might scatter passengers, or water, or oil or dishwashers all over the landscape! On the other hand, it might have been the manufacturer's supply chain that failed. 


\section{Education}

If you take the larger view, the broader notion of what a supply chain is, then educational systems also have them. When we consider curriculum changes for a college bachelor's degree, we talk about the pipeline effect, whereby changes in early years will not show up in the graduating class for perhaps four years. There is also the supply of teachers, funds, and infrastructure issues to consider.

Many schools have elected to send students home or elsewhere and provide distance education as an alternative to classroom instruction. Some distance education was occurring at the college level before COVID-19 when it made sense from a physical, pedagogical, or economic point of view. We would expect colleges and universities to adapt faster and probably perform better at this than $\mathrm{K}-12$, since many have prior experience and are better equipped. They also have more nuanced responses to their specific situations.

The sudden and massive shift of K-12 to distance in the spring of 2020 and then again this fall is more of a problem. It seems more due to the lack of any better solution from either a political or pedagogical view and some magical thinking on the part of politicians and public-school officials. On the surface, distance education appears to provide the same education as classroom instruction without the risk of COVID-19 transmission. Thus, two problems are neatly solved. Unfortunately, many K-12 teachers, students, and parents have no experience with distance learning. There are big equipment and network issues, delays, and costs. I have designed, constructed, and taught several online courses. My experience is that you do not get to know the students as soon or as well; that it takes twice as much time, effort and money to do it properly; and that the quality of education can suffer. In addition, a sudden change to distance education appears to further handicap already disadvantaged groups and makes employment more difficult for parents. One recent example of this political thinking made headlines when Dr. Barbara Ferrer, a Director of the Los Angeles County Department of Public Health, said on national television that she did not think that LA schools would reopen until after the presidential election. One has to wonder why a presidential election should affect the date when it is safe for schools reopen.

Fortunately, there is a vaccine (several candidates) on the horizon that may be available late this year or early next year. With issues of distribution and perhaps the need for two inoculations it is uncertain how much of the 2020-2021 school year will be affected. After that, will we return to "normal"?

\section{Research}

I once saw a bumper sticker that said: "If you think education is expensive, think about ignorance." Research is something that depends heavily on education at both the college and graduate level. According to the Council of Graduate Schools (CGS) the demand for M.S. and Ph.D. training is expected to be expanding at about 1 to $2 \% / y e a r$ through 2028, with heaviest needs in the math and health sciences areas and somewhat less in engineering and other STEM areas (Hironao 2020). Clearly, research is working overtime in the health sciences areas, especially in the search for vaccines and COVID-19 treatments. It is hard to tell for certain, but my feeling is that much of government funding for other research is being maintained at least at a level such that most programs will survive until next year. This is a good thing even if productivity is low due to COVID-19 related disruptions. Research organizations are hard to rebuild. 


\section{Graduate Education}

Perhaps some of the most vulnerable research is the smaller-scale university research. This is often funded by a blend of government, private industry, and technical service work in science and engineering and clinical or professional services in the health sciences area. It tends to be short horizon (1 to 3 years duration) projects of fundamental or pre-commercial orientation.

Many campuses are partially closed and services and supply chain issues are creating uncertainty. However, these are some of the smartest and most adaptable people in research. They will find a way! According to the CGS, as of June, $202076 \%$ of reporting campuses have task forces or committees of stakeholders addressing the impact of COVID-19 on graduate education. Most deans anticipate some budget shortfalls and modest declines in enrollment, including minority enrollment. Somewhat larger declines in international student enrollment are expected. Currently, there are some disruptions in travel and visa issues for international students, who often bring some funding with them.

\section{Back to Normal?}

Well that is just a catchy title. We all know that we are not going back to the "old normal." We are going to the "new normal." The question is what will the new normal look like?

Even with a vaccine and the election behind us, handshakes and hugs are going to be rare. We are going to have to recover from trillions of dollars of damage, debt, and destroyed businesses. Education and research will both suffer from a year of difficult and dubious progress, which will be felt long into the future. Hopefully, the recovery will be quick. Hopefully, we will grow and learn from this disaster. Hopefully, we will learn to prepare better for the future. (I am adding masks and way more toilet paper to my hurricane emergency kit). Hopefully, senior care facilities will be better designed and managed. Hopefully we will rethink supply chains that supply critical services and stretch all over the world. Hopefully, we will become more civil, more fair-minded and more conscious of those who have been hurt the worst.

It might also be a great time to reflect and fix some of the problems with our education system. For example: the experiment with distance learning in K-12 has been expensive, painful, and difficult. Perhaps we should seize the moment, incorporate it permanently into our education system in a smaller way, and use it to include parents in their children's education. As wonderful as they are, colleges and graduate programs could use some thought also!

\section{References Cited}

Hironao, O. (2020). "The impact of COVID-19 on Graduate Education," Council of Graduate Schools website, cgsnet.org, June 3, 2020. 